\title{
Patient's Perception on Factors for Choice of Healthcare Delivery at Public Hospitals in Dodoma City
}

\author{
Steven Lee Mwaseba ${ }^{1,}$,, Emmanuel Simon Mwang'onda ${ }^{1}$, Mafuru Solomi Juma ${ }^{2}$ \\ ${ }^{1}$ Department of Rural Development and Regional Planning, Institute of Rural Development Planning, Dodoma, Tanzania \\ ${ }^{2}$ Department Environmental Planning, Institute of Rural Development Planning, Dodoma, Tanzania
}

Email address:

stevenmwaseba@gmail.com (S. L. Mwaseba), emmer2011@gmail.com (E. S. Mwang'onda), mjuma@irdp.ac.tz (M. S. Juma)

${ }^{*}$ Corresponding author

\section{To cite this article:}

Steven Lee Mwaseba, Emmanuel Simon Mwang'onda, Mafuru Solomi Juma. Patient's Perception on Factors for Choice of Healthcare Delivery at Public Hospitals in Dodoma City. Central African Journal of Public Health. Vol. 4, No. 3, 2018, pp. 76-80.

doi: 10.11648/j.cajph.20180403.14

Received: June 6, 2018; Accepted: July 9, 2018; Published: August 4, 2018

\begin{abstract}
Globally health is regarded as a human capital and thus healthcare delivery is treated as of crucial importance to all communities. Both non-price and price factors play a significant role in determining the patient's choice for healthcare delivery providers. Recently public hospitals have shown to face fairly growing community expectations, though they still perceived to have low quality healthcare, thus the intent of the study. Employing Chi-square and five point likert scale questions patient's choice and perception were assessed. The results show that there is greater relationship between age and patient's choices to attend at public hospitals, while education, sex and patient's occupation were not significant. Moreover, treatment cost, distance from the hospital, and location of the hospital and medicine availability were key indicators for patient's choice. Improvement of medicine availability and reduction of treatment cost is needed so as to attract patients in public hospitals. Since patient's choices are not completely rational, further research should be done on health outcome factors that influence patient's choice in order to integrate healthcare provider and health outcome factors towards improvements of quality health services at public hospitals.
\end{abstract}

Keywords: Choice, Healthcare Delivery, Perception, Public Hospitals

\section{Introduction}

Globally health is regarded as a human capital and thus healthcare delivery is treated as of crucial importance to all communities [1-4]. In this respect all nations aim at achieving high quality health services that are accessible, safe, effective and affordable and to the patients.

The role of healthcare delivery mostly falls under government but with supplementing support of religious institutions, non-governmental organization, multilateral and bilateral agencies, refugee and disaster relief organizations United Nations organizations, and donor agencies [5-8].

In Tanzanian context, in order to enhance and captivate human capital available, the health policy targets to improve health and wellbeing of all Tanzanians. The policy focuses on ensuring access to basic health services to the population at risk, and encourages the health system to be more responsive to the needs of the people [9]. To ensure achievement of stated policy objective, the recent health strategy, 'Health sector Strategic plan IV July 2015-2020' was adopted with the aim of reaching all households with quality health care that emphasizes on better performance of health facilities as well as individuals within health system [9].

Health and social welfare services in Tanzania are provided from grassroots level up through higher levels of care by both private and public sectors. The lowest level being community health care, then dispensaries and health centers at village and ward level, and followed by first level hospitals at district level, regional referral hospitals at regional level and; zonal and national hospitals at highest national level [10].

The choice of people to attend for healthcare delivery is of multi dimensional. Others choose basing on healthcare providers, and others on healthcare outcomes [11]. Normally, due to insufficient quality services at primary levels, 
community trust hospitals compared to dispensary and health centers. In many economies, the existing health policies allow the patients to choose where to attend for healthcare services, either at private or public hospitals. However, studies has shown that non-price and price factors play a significant role in determining the patients choice on services provision which make them to latent utility as an outcome [11].

Although private hospitals are regarded to be superior in healthcare delivery, but recently public hospitals has shown to face fairly growing patient's expectations [12], as the health service provision is of most benefit to poor people and is the only way to achieve universal and equitable access to health provision. This is supported by [12] reports, which show that public hospitals are required to provide free treatment.

Despite that most of the people choose attending at public hospitals for healthcare delivery and the reforms made by the government, literature show that patients still perceive that they receive low quality of healthcare [2, 10] and [13-14]. Furthermore, it has been observed in public hospitals that health service provision is constrained by a number of factors including poor infrastructure, unavailability of medicine $\mathrm{s}$ and medical equipment and limited human resources [1-4]. Thus the study wants to explore the perception of patients on the factors influencing them to choose public hospitals for healthcare delivery.

\section{Method}

The study was conducted in Dodoma city municipality, Dodoma Region the capital city of Tanzania. It was selected because of the dominance of public compared to private hospitals (see table 1). Moreover, recently there has been an emphasis of the government headquarter offices and ministries to shift from Dar es Salaam to Dodoma, thus a population increase will have an implication on healthcare delivery due to the need of health as a human capital.

Cross-sectional research design was adopted that allowed the collection of data in public hospitals at single point of time. Both quantitative and qualitative data were collected from the patients attended at a public hospital on the day of enumeration by the use of both structured and unstructured questionnaires; and focus group discussion (FGD).

The questionnaires assessed the socio-demographic characteristics of the respondents, whereby age, sex, education and occupation of the respondent were used. They were used because were seen as important characteristics in determining choice of patients to attend for healthcare delivery [15-17]. Moreover the questionnaires assessed the perception of the patients on factors that determine their choice to attend at a public hospital for healthcare delivery.

The patients attended at a public hospital during the day of enumeration served as a sample frame. The sampling techniques used were simple random and judgmental sampling. Simple random sampling was used to collect data from the patients attended at the hospital and judgmental sampling was used to obtain data from a key informant. A total of 96 respondents were attended for the data collection exercise.

Relationship between socio-demographic characteristics of the patients and the choice of the patients to attend at public hospital for healthcare delivery was established using Chisquare. The choice looked at whether the patient attends by his/her will or not.

The term perception of the patient on the factors to choose public hospital for healthcare delivery was analyzed by the use of a five point Likert scale with the options; strongly agree, agree undecided, disagree and strongly disagree [18].

On assessing it the following indicators were adopted from various studies and used; physicians and medical treatments, bedside care, staff care to the patients, waiting times, hospital facilities, staff competence and privacy, hospital organization, cleanliness of the hospital, distance, location of the hospital, treatment cost, population at the hospital, religious affiliation, political affiliation and medicine availability [19-22]. The indicators focused mostly on health provider and not on the outcome from healthcare delivery. This helped to know the behavioral characteristic implications to the public policy on healthcare providers in the Dodoma.

Moreover to know the factors that are significant in determining the choice of the patients to attend at a public hospital for healthcare delivery, Pearson Chi-square was used. Later the results were presented in the form of table and words.

\section{Results and Discussions}

\subsection{Results}

Dodoma municipality has five hospitals, three owned by the government, and two owned by Religious institutions. Moreover, there are thirteen health centers, fifty-two dispensaries as shown in table 1. The table indicates the domination of public facilities. The municipality has got the opportunity district, regional and specialized hospitals.

Table 1. Number of Health Facilities in Dodoma City.

\begin{tabular}{llll}
\hline Health Facilities & Public & Private & Total \\
\hline Hospitals & 3 & 2 & 5 \\
Health centers & 8 & 5 & 13 \\
Dispensaries & 36 & 16 & 52 \\
\hline
\end{tabular}

Source: Dodoma Regional Hospital (2017).

\subsubsection{Socio-demographic Characteristics of the Patients}

The study used 96 patients, among them 53.1\% were females and $46.9 \%$ were males. Youth is the group that has shown to be attending more at public hospitals in the study elders, while no elder show up during the day of enumeration (See table 2). $47.9 \%$ of the patients has attended college education and few of them attended at least primary education, most of them being public employee (see table 2). 
Table 2. Socio-demographic Characteristics of the Patients.

\begin{tabular}{lll}
\hline Variable & Number of Observations & Per cent \\
\hline Sex of Respondent & & \\
Male & 45 & 46.9 \\
Female & 51 & 53.1 \\
Age of Respondent & & \\
$15-35$ & 79 & 82.3 \\
$35-64$ & 17 & 17.7 \\
Education Level & & \\
Non Formal Education & 11 & 11.5 \\
Primary school Education & 10 & 10.4 \\
Secondary School Education & 16 & 16.7 \\
College & 46 & 47.9 \\
University Education & 13 & 13.5 \\
Occupation of Respondent & & \\
Farming & 26 & 27.1 \\
Livestock Keeping & 1 & 1.0 \\
Business & 13 & 13.5 \\
Public Employee & 35 & 36.5 \\
Private Employee & 17 & 17.7 \\
Student & 4 & 4.2 \\
\hline
\end{tabular}

\subsubsection{Correlation Between Socio-demographic Characteristics and Patient's Choice on Healthcare Delivery in Dodoma}

In establishing this relationship, first the descriptive analysis of choice was done, and the results show that most of the patients choose to attend at public hospitals for healthcare delivery by their will. About $87.5 \%$ of the patients attended at the hospital by their will and the rest $12.5 \%$ are not of their will.

Using Pearson Chi-Square, the study investigated the correlation between the selected socio-demographic characteristics (education, age, sex and occupation) and the patient's choice. The results show that only age was significant and at $1 \%$ on determining the choice of the respondents on attending at public hospitals for healthcare delivery in the study area, more specifically large group is youth who were $82.3 \%$, the rest were adult $17.7 \%$ and elders didn't show up (see table 2). Moreover patient's occupation, education and sex have seen to be not significance sociodemographic characteristics on choosing to attend at public hospitals for healthcare delivery.

\subsubsection{Patient's Perception on the Factors for the Choice of Healthcare Delivery at Public Hospitals in Dodoma}

The study intended to explore the perception of the patients on the factors for their choice of healthcare delivery at public hospitals, the selected indicators has been shown in table 3 below Tracing on perception, the results show that the patients strongly agreed and agree on treatment cost, distance from the hospital, location of the hospital and medicine availability as the key indicators for their choice to attend at public hospitals for health care delivery (see table 3). Moreover the results revealed that the patients perceived that physicians and medical treatments, bedside care, staff care to the patients, waiting times, hospital facilities, staff competence and privacy, hospital organization, cleanliness of the hospital, population at the hospital, religious affiliation and political affiliation as not influential indictors for them to attend at public hospitals for healthcare delivery (see table 3).

Although cleanliness of the hospital, waiting time and religious affiliation were perceived by the patients to be not important indicators, but using Chi Square to investigate the important factors for patient's choice to attend at public hospitals for service delivery the indicators were significant at $5 \%$ (see table 3). Moreover from their perception, the patients agreed on medicine availability and treatment cost as important indicators, the answer was similar when Chisquare used and the variables were significant at $1 \%$ and $5 \%$ respectively (see table 3 ).

Table 3. Patient's Perception and Determinants for the Choice of Public Hospitals for Healthcare Delivery in Dodoma City.

\begin{tabular}{|c|c|c|c|c|c|}
\hline Indicator & Strongly Agree (\%) & Agree (\%) & Disagree (\%) & Strongly Disagree (\%) & Pr. Chi-Square \\
\hline Physicians and medical treatments & 0 & 20.8 & 67.7 & 11.5 & 0.126 \\
\hline Bedside care & 0 & 10.4 & 65.6 & 24 & 0.380 \\
\hline Staff care to the patients & 1 & 7.3 & 66.7 & 25 & 0.422 \\
\hline Waiting times & 0 & 3.1 & 63.5 & 33.3 & $0.031^{* *}$ \\
\hline Hospital facilities & 1 & 11.5 & 52.1 & 35.4 & 0.093 \\
\hline Staff competence and privacy & 1 & 16.7 & 37.5 & 44.8 & 0.122 \\
\hline Cleanliness of the hospital & 1 & 3.1 & 28.1 & 67.7 & $0.020^{* *}$ \\
\hline Distance from the hospital & 66.7 & 19.8 & 9.4 & 4.2 & 0.572 \\
\hline Location of the hospital & 49 & 30.2 & 17.7 & 3.1 & 0.757 \\
\hline Treatment cost & 88.5 & 8.3 & 1 & 2.1 & $0.045^{* *}$ \\
\hline Population at the hospital & 4.2 & 10.4 & 54.2 & 31.3 & 0.754 \\
\hline Religious affiliation & 0 & 2.1 & 34.4 & 63.5 & $0.033^{* *}$ \\
\hline Political affiliation & 0 & 1 & 31.3 & 67.7 & 0.094 \\
\hline
\end{tabular}

Asterisks $* * *$ and $* *$ means significant at $1 \%$, and $5 \%$ respectively.

NB: Option undecided is not seen in the table because no patient selected it.

\subsection{Discussion}

Most of the patients attend at public hospitals in Dodoma city for healthcare delivery is of their will. The study also has shown that among the socio-demographic characteristics used age is very important indicator in determining patient's 
choice [15-17]. The result has also shown that the group who attend mostly are youth who were about $82.3 \%$ and adults about $17.7 \%$, though other studies has shown that elders is the group who attend in large percent in the hospitals due to the fear of their health than youth and adults. Education, sex and occupation [15] of the patients have shown to be not influential socio-demographic characteristics on choice to attend at a public hospital for healthcare delivery.

Furthermore using a five-likert scale the study investigated the perception of the patients on the factors for choice of healthcare delivery at public hospitals. By focusing on health provider characteristics the results show that the patients strongly agreed and agree on treatment cost [16] and [23-25] distance from the hospital [23] and [25-27], location of the hospital [23] and medicine availability [23-24] as the key indicators.

The choice has based much on non-personnel factors. The patients need short distance from the hospital; treatment cost to be minimal as it is observed in many public hospitals though quality is crucial and thus the patients choose the provider that best fits their needs [23]. Also the patients attend to the public hospital because the location is in township as well as the availability of medicine has shown to be very crucial.

Moreover to know the influential factors on patients choice to attend at a public hospital for healthcare delivery, Chisquare was used to establish the relationship and it was observed that cleanliness of the hospital [28-29] waiting time and religious affiliation were significant though were perceived by the patients to be not important indicators. This implies that even though patients perceived the indicators to of less significant, but in operationalization the public hospitals must consider them in order to attract more customers for service delivery. Medicine availability $[15,24]$ and treatment cost $[16,13,25]$ were perceived by the patients to be important indicators for their choice as well Chi-square revealed that they are important factors for patient's choice.

\section{Conclusion and Recommendations}

\subsection{Conclusion}

The study investigated on the patient's perception on factors for choice of healthcare delivery at public hospitals in Dodoma City. Perception of the patients was measured by a use of a five-likert scale. The factors influencing patient's choice were obtained using Chi-square, which established the relationship between the selected indicators for patient's choice and patient's choice. The results show that $87.5 \%$ of the patients said that they attended at the hospital for their will and the rest $12.5 \%$ not by their will. In establishing the relationship between patient's choice and some selected socio-economic characteristics (education, age, sex and patient's occupation) Chi-square was used; whereby only age was significant at $1 \%$, and large group being youth $(82.3 \%)$ implying that youth is common group attending at public hospitals in Dodoma city.
Lastly using Chi-square to establish relationship between patient's choice and the choice selected indicators; medicine availability, religious affiliation, treatment cost and cleanliness of the hospital and waiting time were seen as influencing indictors for patient's choice. Though looking at their perception; religious affiliation, cleanliness of the hospital and waiting times were disagreed to be the indicators for their choice. The contradiction comes because the degree of choice for some patients is limited and most patients are unable to do have a complete rational choice.

\subsection{Recommendations}

Recently in order to capture the available customers and improve health of the communities so as to improve human capital there is a need for public healthcare providers to take into consideration on medicine availability, treatment cost, waiting times and cleanliness of the hospitals. Because patient's choices are not completely rational, in long run the indicators of choice for healthcare delivery that has shown to be not significant should be taken into consideration for public hospitals to attain income as well as improvement of human capital as a whole, hence quality service provision will be assured [23].

The study explored much on hospitals attributes towards patient's choice that is much more on health service provider. Further research is needed to explore factors influencing patient's choice to attend at public hospital basing on the health outcome. This will enable to integrate healthcare provider and health outcome factors towards improvements of quality health services at public hospitals.

\section{References}

[1] Songstad, N. G., Rekdal, O. B., Massay, D. A. \& Blystad, A. (2011) Perceived unfairness in working conditions: The case of public health services in Tanzania. BMC Health Services Research 11: 34.

[2] Ministry of Health, (2003) Tanzania National Health Policy. The United Republic of Tanzania, Ministry of Health. Dar es Salaam, Tanzania.

[3] Kruk, M. E. \& Freedman, L. P. (2008) Assessing health system performance in developing countries: A review of literature. Health Policy 85, 263-276.

[4] Munga, M. A. \& Mwangu, M. (2013) Comprehensive health workforce planning: reconsideration of the primary health care approach as a tool for addressing the human resource for health crisis in low and middle income countries. Tanzania Journal of Health Research 15, 1-16.

[5] Basu, S., Andrews, J., Kishore, S., Panjabi, R., \& Stuckler, D. (2012). Comparative performance of private and public healthcare systems in low- and middle-income countries: A systematic review. PLoS Medicine, 9(6), 19. https://doi.org/10.1371/journal.pmed.1001244

[6] Chi, Y. L., \& Bump, J. B. (2018). Resource allocation processes at multilateral organizations working in global health. Health Policy and Planning, 33(May), i4-i13. https://doi.org/10.1093/heapol/czx140 
[7] De Wolf, A. H., \& Toebes, B. (2016). Assessing private sector involvement in health care and universal health coverage in light of the right to health. Health and Human Rights, 18(2), 79-92.

[8] Jayasinghe, S. (2007). Faith-based NGOs and healthcare in poor countries: A preliminary exploration of ethical issues. Journal of Medical Ethics, 33(11), 623-626. https://doi.org/10.1136/jme.2006.018549

[9] URT Ministry of Health and Social Welfare (2015), Health Sector Strategic Plan July 2015-June 2020: Reaching all Household With Quality Health Care

[10] MoHSW (2007) Primary Health Services Development Programme 2007-2017. United Republic of Tanzania, Ministry of Health and Social Welfare. Dar es Salaam, Tanzania.

[11] Moscelli G., Luigi S., Nills G. and Cookson R. (2017), Socioeconomic Inequality of Access to Health Care: Does Choice explain the gradient? J. Health Economic

[12] WHO (2015), World Health Statistics. WHO Luxembourg

[13] Khamis, K. \& Njau, B. (2014) Patients' level of satisfaction on quality of health care at Mwananyamala hospital in Dar es Salaam, Tanzania. BMC Health Services Research 14:400.

[14] WHO (2006) The World Health Report, Working together for health. World Health Organization, Geneva, Switzerland.

[15] Al-Doghaither A. H, Abdelrhman B. M, Saeed A. A. W \& Maqzoub M. E. M. A (2003), Factors influencing patient choice of hospitals in Riyadh, Saudi Arabia. Sage Journals Volume: 123 issue: 2, page (s): 105-109

[16] Saeed, S. K. B (1998). Factors affecting patient's choice of hospitals. Annals of Saudi Medicine, 18(5), 420-424

[17] Halasa, Y., \& Nandakumar, A. K. (2009). Factors determining choice of healthcare provider in Jordan. Eastern Mediterranean Health Journal, 15(4), 959-96

[18] Vagias W. M, (2006) Likert-type scale response anchors. Clemson International Institute for Tourism \& Research Development, Department of Parks, Recreation and Tourism Management. Clemson University

[19] Uchendu O. C, Ilesanmi O. S, \& Olumide A. E, (2013) Factors
Influencing the Choice of Healthcare Providing Facility among Workers in a Local Government Secretariat in South Western Nigeria. Annals of Ibadan Postgraduate Medicine vol. 11 (2): 87-95

[20] Bozic, K. J., Kaufman, D, Chan, V. C., Caminiti, S. \& Lewis, C. (2013). Factors that influence provider selection for elective total joint arthroplasty. Clinical Orthopaedics and Related Research, 471(6), 1865-1872.

[21] Kamra, V., Singh, H., \& De, K. K. (2016). Factors affecting hospital choice decisions: An exploratory study of healthcare consumers in Northern India. Asia Pacific Journal of Health Management, 11(1), 76-84.

[22] Ghosh, M. (2015). An empirical study on hospital selection in India. International Journal of Healthcare Quality Assurance, 28(1), 1-19.

[23] Abiodun O. A et al., (2014) The determinants of Choice of Health Facility in Sagamu, South-West, Nigeria. Scholars Journal of Applied Medical Sciences, 2014; 2(1C):274-282.

[24] Victoor A, Delnoij D. M \& Friele R. D (2012), Determinants of patient choice of healthcare providers: a scoping review. BMC Health Services Research 2012 12:272.

[25] Amaghionyeodiwe A. L (2008) Determinants of the choice of health care provider in Nigeria. Health Care Management Science (2008) 11:215-227.

[26] He J, Hou XY, Toloo GS \& FitzGerald G. (2017). Patients' choice between public and private hospitals emergency departments: A cross-sectional survey, Emerg Med Australas 29(6): 635-642.

[27] He J, Hou XY, Toloo GS \& FitzGerald G. (2016). Qualitative study of patients' choice between public and private hospital emergency depatments, Emerg Med Australas 28(2): 159-63.

[28] Vonberg, R. P., Sander, C., \& Gastmeier, P. (2008). Consumer attitudes about healthcare acquired infections: A German survey on factors considered important in the choice of a hospital. American Journal of Medical Quality, 23(1), 56-59.

[29] Akinci, F., Esatoglu, A. E., Tengilimoglu, D., \& Parsons, A. (2008). Hospital choice factors: A case study in Turkey. Health Marketing Quarterly, 22(1), 3-19. 